\title{
Influence of Biocompatible Coating on Titanium Surface Characteristics
}

\author{
Željka Petrović ${ }^{1, *}$, Jozefina Katić ${ }^{2}$, Ankica Šarić ${ }^{3}$, Ines Despotović ${ }^{4}$, Nives Matijaković ${ }^{1}$, Damir \\ $\mathrm{Kralj}^{1}$, Mirela Leskovac ${ }^{5}$ and Marin Petković ${ }^{6}$
}

\begin{abstract}
${ }^{I}$ Division of Materials Chemistry, Rudjer Boskovic Institute, Bijenicka cesta 54, Zagreb 10002, Croatia; ${ }^{2}$ Department of Electrochemistry, Faculty of Chemical Engineering and Technology, University of Zagreb, Zagreb 10000, Croatia; ${ }^{3}$ Division of Materials Physics, Centre of Excellence for Advanced Materials and Sensing Device, Rudjer Boskovic Institute, Bijenicka cesta 54, Zagreb 10002, Croatia; ${ }^{4}$ Division of Physical Chemistry, Rudjer Boskovic Institute, Bijenicka cesta 54, Zagreb 10002, Croatia; ${ }^{5}$ Department of Polymer Engineering and Organic Chemical Technology, Faculty of Chemical Engineering and Technology, University of Zagreb, Zagreb 10000, Croatia; ${ }^{6}$ Department of Dental Implantology, Adentro dental Studio, Zagreb 10000, Croatia
\end{abstract}

\begin{abstract}
Background: Nowadays investigations in the field of dental implants engineering are focused on bioactivity and osseointegration properties.

Objective: In this study, the oxide-covered titanium was functionalized by vitamin D3 molecules via a simple self-assembly method with the aim to design more corrosion-resistant and at the same time more bioactive surface.

Methods: Surface properties of the D3-coated titanium were examined by scanning electron microscopy, attenuated total reflectance Fourier transform infrared spectroscopy, and contact angle measurements, while long-term corrosion stability during immersion in an artificial saliva solution was investigated in situ by electrochemical impedance spectroscopy.

Results: Results of all techniques confirmed a successful formation of the vitamin D3 layer on the oxide-covered titanium. Besides very good corrosion resistivity $\left(\sim 5 \mathrm{MW} \mathrm{cm}^{2}\right)$, the D3-modified titanium surface induced spontaneous formation of biocompatible bone-like calcium phosphates $(\mathrm{CaP})$
\end{abstract}

A R T I C L E H I S T O R Y

Received: December 17, 2019

Revised: March 05, 2020

Accepted: March 16, 2020

DOI:

10.2174/2352094910999200407095723
Conclusion: Observed in vitro CaP-forming ability as a result of D3-modified titanium/artificial saliva interactions could serve as a promising predictor of in vivo bioactivity of implant materials.

Keywords: Titanium, vitamin D3, self-assembly, surface coating, calcium phosphates, corrosion properties.

\section{INTRODUCTION}

It is well-known that an implantation success depends on the process of osseointegration, which was first described by Swedish professor Brånemark, "father of modern dental implantology" $[1,2]$. This discovery, that bone can be effectively fixed to the implant without its rejection, launched a new era of investigations and development of dental implant materials $[3,4]$. From that time until the last decade, the research focus shifted from the implant's design and geometry to the osseoinductive properties of implant surfaces.

Current trends in dental implant research are based on surface properties modifications by biomimetic and bioactive coatings that mimic biochemical surroundings and architecture of the human bone [3-5]. Calcium phosphate ceramics, like hydroxyapatite, with a mineral composition similar to natural bone, as a single compound coating or as a composite with collagen, bioglass, or silica are used to promote

${ }^{*}$ Address correspondence to this author at the Division of Materials Chemistry, Rudjer Boskovic Institute, Bijenicka cesta 54, Zagreb 10002, Croatia; Tel: +38591 7684985; E-mail: zpetrov@irb.hr osseointegration or overall implant system's characteristics $[6,7]$. Peptide RGD coatings that facilitate cell adhesion during osseointegration are also used to design novel implant surfaces [8]. Drug-based coatings with bisphosphonates like Zolendronate [9] or Alendronate [10, 11], drugs for bone diseases, promote mechanical fixation of implant and bone mineralization.

However, it must not be forgotten that a fundamental prerequisite for the success of osseointegration is the longterm corrosion stability of implant materials. Human body fluids, especially oral cavity fluids, in which $\mathrm{pH}$ is constantly changing, represent very aggressive media with high concentrations of chloride ions that are among the most aggressive and corrosive to metals [12]. Although titanium is a gold standard in dental implantology due to its exceptional biocompatibility and corrosion resistivity $[12,13]$, there is increasing data reported regarding complications caused by titanium dental implant fixation. It was shown that titanium ions, that originated as a product from corrosion reaction in body fluids, caused negative immune reactions or skin allergies immediately or shortly after implant fixation [14-16]. 
Therefore, it is crucial to design a coating which will make titanium surface more bioactive/osseoinductive and at the same time more corrosion resistant during long-term exposure to oral cavity fluids.

In this study, the titanium surface was modified by vitamin D3, molecules that are crucial for the normal functioning of the immune system [17] and maintaining bone mineral density [18]. The main goals were (i) to improve titanium corrosion resistivity during exposure to an artificial saliva solution; and simultaneously (ii) to induce in vitro processes of "new bone" formation. In our previously published paper, a D3 coating formation mechanism on the oxide-covered titanium dental implant was explained in detail by DFT method [19] whereas this research is a follow up to the previous study and herein long-term corrosion behavior of the vitamin D3-modified titanium surface in an artificial saliva solution was investigated in situ by electrochemical impedance spectroscopy. To the best of our knowledge, surface characteristics of bioactive coatings on dental implants are in the focus of current research in this field, but their corrosion stability has not been sufficiently investigated.

\section{MATERIALS AND METHODS}

\subsection{Chemicals, Materials, and Ti Surface Coating For- mation}

The following chemicals were used as received: Vitamin D3 drops $\left(122 \mu \mathrm{mol} \mathrm{dm}{ }^{-3}\right.$ cholecalciferol in aqueous glycerol solution; ChildLife ${ }^{\circledR}$, USA), acetone (p.a., Gram-Mol ${ }^{\circledR}$, Croatia), and absolute ethanol (p.a., Gram-Mol ${ }^{\mathbb{B}}$, Croatia). The titanium discs (Ti, 99.9\%, Alfa Aesar ${ }^{\circledR}$, Karlsruhe, Germany) of $12 \mathrm{~mm}$ in diameter were used as substrates for bioactive coating formation.

The Ti surfaces were abraded with SiC emery papers of \#240 to \#600 grit, ultrasonically cleaned with absolute ethanol and redistilled water, and dried in a stream of nitrogen $(99.999 \%$, Messer ${ }^{\mathbb{B}}$, Germany). Prepared Ti discs were electrochemically treated in order to prepare an oxide-covered $\mathrm{Ti}$ surface needed for a successful vitamin D3 bonding [19]. The oxide layer on the $\mathrm{Ti}$ (Ti/oxide) was formed potentiostatically at the film formation potential, $E_{\mathrm{f}}=2.5 \mathrm{~V} v s \mathrm{Ag}|\mathrm{AgCl}| 3 \mathrm{~mol}$ $\mathrm{dm}^{-3} \mathrm{KCl}$ during 24 hours in a phosphate buffer solution $\left(0.075 \mathrm{~mol} \mathrm{dm}^{-3} \quad \mathrm{Na}_{2} \mathrm{HPO}_{4} \cdot 7 \mathrm{H}_{2} \mathrm{O}+0.025 \mathrm{~mol} \mathrm{dm}^{-3}\right.$ $\mathrm{NaH}_{2} \mathrm{PO}_{4} \cdot 2 \mathrm{H}_{2} \mathrm{O}, \mathrm{pH}$ 7.4). The Ti/oxide samples were rinsed with redistilled water and dried in a stream of nitrogen. The vitamin D3 layer onto the Ti surface was produced by immersion of the Ti/oxide samples in vitamin D3 solution at 21 $\pm 1{ }^{\circ} \mathrm{C}$ for 24 hours. Thereafter, the modified samples were dried in a regular air-convection oven $\left(\right.$ Memmert $^{\mathbb{B}}$, Schwabach, Germany) at $70{ }^{\circ} \mathrm{C}$ for 5 hours according to previously reported procedures $[19,20]$. Ti/oxide/D3 samples were additionally rinsed with absolute ethanol and redistilled water and dried in a stream of nitrogen. Thus, prepared Ti/oxide and Ti/oxide/D3 samples are denoted in the text as-prepared samples.

\subsection{Characterization Methods}

The characterization of samples was performed by contact angle measurements (CA), attenuated total reflectance Fourier transform infrared spectroscopy (ATR-FTIR), thermal field emission Scanning Electron Microscopy (SEM), energy dispersive X-ray analysis (EDS) and electrochemical impedance spectroscopy (EIS).

The contact angle measurements were carried out by a contact angle system OCA 20 (Dataphysics Instruments GmbH, Germany) at $21 \pm 2{ }^{\circ} \mathrm{C}$ using Milli- $\mathrm{Q}^{\mathbb{R}}$ water, formamide and diiodomethane at the dosing volume of $1 \mu \mathrm{l}$. Values were measured after a 10s-stabilization period at different surface positions. The surface free energy of investigated surfaces was calculated by the software SCA 20 ver. 2.01.

A Tensor II spectrometer (Bruker Optik GmbH, Ettlingen, Germany) was used for ATR-FTIR measurements in the wavenumber range between 4000 and $340 \mathrm{~cm}^{-1}$ at $4 \mathrm{~cm}^{-1}$ scan step and total 16 scans per measurement.

The morphology of the samples was examined by a thermal field emission scanning electron microscope (model JSM-7000F, Jeol Ltd., Tokyo, Japan) connected to the Oxford Instruments EDS/INCA 350 energy dispersive X-ray ar-1.zer for elemental analysis.

Tic corrosion properties of Ti samples in an artificial saliva solution electrolyte, $\mathrm{pH} 6.8$ were explored by EIS at the open circuit potential, $E_{\mathrm{OC}}$ during immersion period of 1 hour and 1month. The measurements were performed with an $a c$ voltage amplitude of $\pm 5 \mathrm{mV}$ in the frequency range from $10^{5}$ to $10^{-3} \mathrm{~Hz}$ by using Solartron 1287 potentiostat/galvanostat with Solartron FRA 1260 (Solartron Analytical, UK) controlled by ZPlot ${ }^{\mathbb{R}}$ software v. 3.5e. The complex non-linear least squares (CNLS) fit analysis [21] ZView ${ }^{B}$ software v. $3.5 \mathrm{e}$ was employed to model experimental data with $\chi^{2}$ values less than $5 \times 10^{-3}$ (errors in parameter values of $1-5 \%$ ). The measurements were performed in a standard threeelectrode cell (Corrosion Cell K0047, Princeton Applied Research, USA) with a Pt electrode as a counter electrode and a reference electrode, $\mathrm{Ag}|\mathrm{AgCl}| 3.0 \mathrm{~mol} \mathrm{dm}^{-3} \mathrm{KCl}(E=$ $0.210 \mathrm{~V} v s$. standard hydrogen electrode, SHE) to which all potentials in the paper are referred. The Ti samples served as a working electrode (an area exposed to the electrolyte, $A=$ $\left.0.98 \mathrm{~cm}^{2}\right)$. The Fusayama artificial saliva $\left(0.4 \mathrm{~g} \mathrm{dm}^{-3} \mathrm{NaCl}\right.$, $0.4 \mathrm{~g} \mathrm{dm}^{-3} \mathrm{KCl}, 0.6 \mathrm{~g} \mathrm{dm}^{-3} \mathrm{CaCl}_{2} \cdot 2 \mathrm{H}_{2} \mathrm{O}, 0.58 \mathrm{~g} \mathrm{dm}^{-3}$ $\mathrm{Na}_{2} \mathrm{HPO}_{4} \cdot 2 \mathrm{H}_{2} \mathrm{O}$, and $1 \mathrm{~g} \mathrm{dm}^{-3}$ urea), pH 6.8 [22], prepared from p.a. grade chemicals and redistilled water, was an electrolyte solution.

\section{RESULTS AND DISCUSSION}

\subsection{Morphological and Chemical Properties of Ti Samples}

Scanning electron microscopy (SEM) was used to characterize surface features of investigated samples. The morphologies of Ti/oxide and Ti/oxide/D3 samples before (asprepared samples) and after a 1-month immersion period in an artificial saliva solution are presented in Fig. (1). As can be seen, the oxide layer, prepared potentiostatically on the $\mathrm{Ti}$ surface, is characterized by a layered-structure and can be divided into two regions: (i) the outer region grown near the oxide layer/phosphate buffer solution interface - inhomogeneous with cracks; and (ii) the inner region grown near the Ti/oxide layer interface - more homogeneous and compact. The D3 layer, self-assembled on the Ti/oxide surface, did not change notably the surface morphology due to its low thickness according to our DFT calculations [19]. Besides, it is known that self-assembled films, which are of a monolayer 
a)

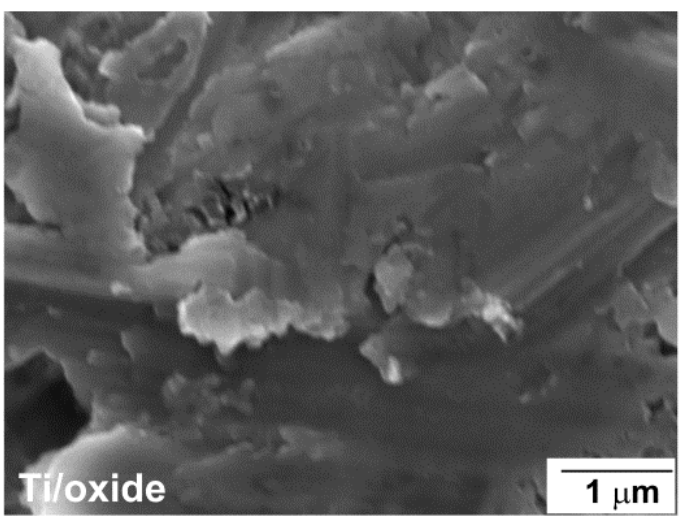

c)

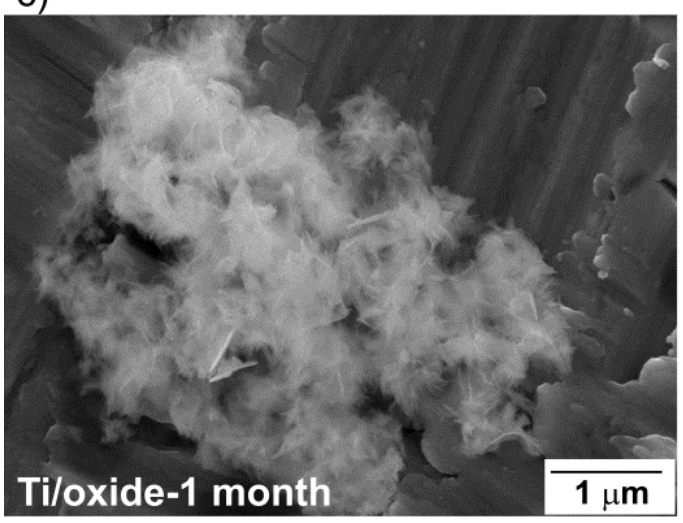

b)

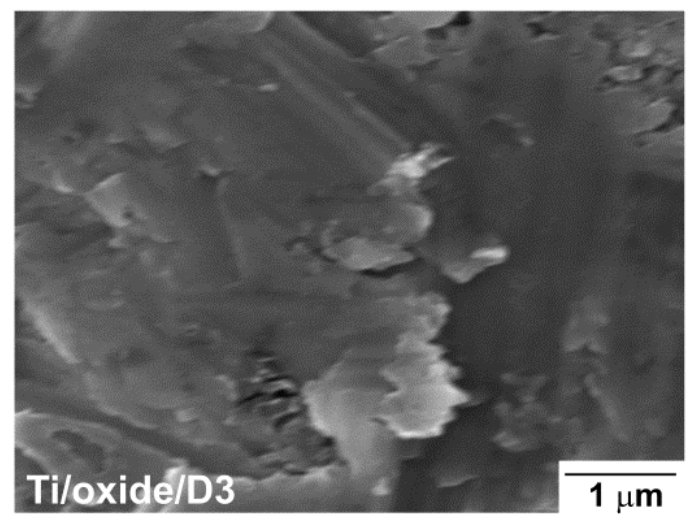

d)

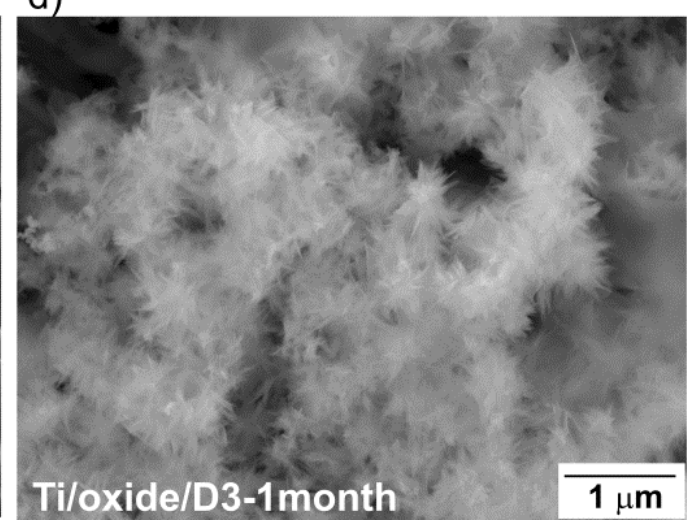

Fig. (1). SEM images of Ti/oxide and Ti/oxide/D3 samples: (a, b) before and (c, d) after 1 month-immersion period in the artificial saliva solution. (A higher resolution / colour version of this figure is available in the electronic copy of the article).

thickness (up to $2 \mathrm{~nm}$ ), do not influence significantly morphological or other characteristics of the substrate [23].

After a 1-month immersion period of both samples in an artificial saliva solution, the morphology was preserved, but white island features appeared that were also visible by the naked eyes, Figs. (1c, 1d). A deep insight into white islands, Fig. (2a) shows 3D architecture composed of flower-like agglomerates (up to $1 \mathrm{~mm}$ ) self-assembled from needleshaped nanosized units. A process of 3D flower-architecture formation on both surfaces under experimental conditions (1 month, room temperature, $\mathrm{pH}=6.8$, and ions present in artificial saliva) was self-induced.

The elemental analysis identified titanium and oxygen on the as-prepared Ti/oxide surface and titanium, oxygen, and carbon on the as-prepared Ti/oxide/D3 surface, Fig. (1a, b). On the samples immersed for 1 month in the artificial saliva solution $\mathrm{Ca}, \mathrm{P}, \mathrm{Cl}, \mathrm{Na}, \mathrm{K}, \mathrm{O}, \mathrm{C}$, and $\mathrm{Ti}$ existed in the region of the white islands features, Fig. (2a, b), since in the grey region, $\mathrm{Ti}$ and $\mathrm{O}$ were mainly present. Henee, 3D-flower architectures are spontaneously formed due to the chemical eompesition of ealeium phosphates, $\mathrm{CaP} . \mathrm{CaP}$ is the main component of natural bone tissues along with other trace elements ( $\mathrm{Na}, \mathrm{K}, \mathrm{O}, \mathrm{F}, \mathrm{Mg}$, and $\mathrm{Cl}$ ) and it can be found in the form of crystalline hydroxyapatite (HAp) or amorphous calcium phosphate (ACP) [24-26].
According to the elemental analysis, Fig. (2b), Ca/P atomic ratio is equal to 1.42 and most probably points to an amorphous calcium phosphate, $\mathrm{ACP} ; \mathrm{Ca}_{\mathrm{x}} \mathrm{H}_{\mathrm{y}}\left(\mathrm{PO}_{4}\right)_{\mathrm{z}} \cdot \mathrm{nH}_{2} \mathrm{O}, \mathrm{n}=$ $3-4.5 ; 15-20 \% \mathrm{H}_{2} \mathrm{O}(\mathrm{Ca} / \mathrm{P}=1.2-2.2)$ [24-28]. Due to trace elements detected $(\mathrm{Cl}, \mathrm{Na}, \mathrm{K}, \mathrm{O}, \mathrm{C})$, the $\mathrm{CaP}$ is biocompatible bone-like $\mathrm{CaP}$ that is always nonstoichiometric with structural imperfections co-substituted in the crystal lattice. The presence of trace elements in the $\mathrm{CaP}$ formed is an advantage due to their important roles in biological processes, especially in bone metabolism and activation of osteoclasts [25]. Larger agglomerates in a higher amount appeared on the Ti/oxide/D3 surface in comparison to the Ti/oxide surface, as shown in Fig. (1c, d). According to the elemental analysis, white islands deposits of very similar composition with the $\mathrm{Ca} / \mathrm{P}=1.40$ were formed on the Ti/oxide surface.

The fabrication and properties of $3 \mathrm{D}$ architectures (porous spheres, enamel-like structures, 3D flowers, etc.) of biological materials like hydroxyapatite and other $\mathrm{CaP}$ forms have attracted great interest due to their enhanced biological performances [25]. Their synthesis is usually carried out in the presence of surfactant, template supporting or structuredirecting reagents $[25,28,29]$, therefore spontaneous $\mathrm{CaP}$ formation closely resembling human bones, makes investigated surfaces osseoinductive. Thus, it can be concluded that the organic D3 vitamin top layer acted as a CaP growthpromotor that stimulated nanoneedles growth as well as their self-assembly in 3D architectures. In addition, it is well 
a)

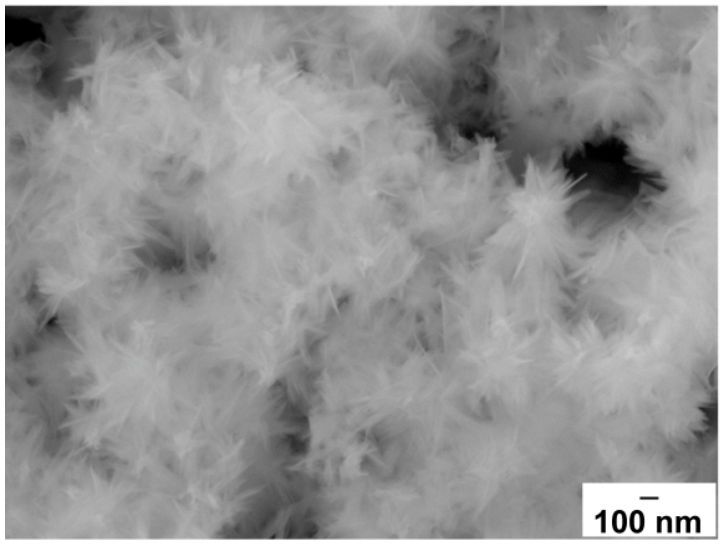

b)

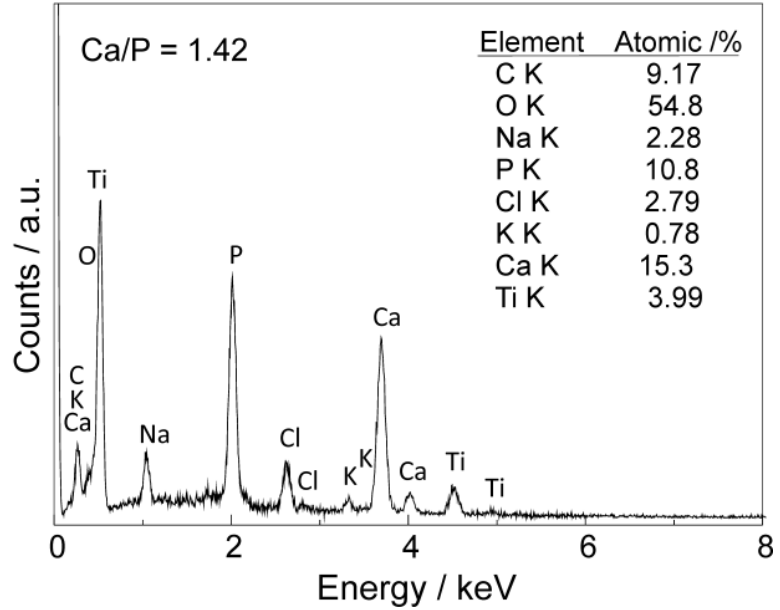

Fig. (2). (a) The morphology of white deposit features spontaneously formed on the Ti/oxide/D3 surface during 1 month-immersion period in the artificial saliva solution; and (b) corresponding EDS spectrum and chemical composition of the deposit. (A higher resolution / colour version of this figure is available in the electronic copy of the article).

known that vitamin D3 is a key factor for the calcium homeostasis [30] and thus, the titanium surface covered with the D3 vitamin layer is indeed biocompatible since it could attract more calcium and phosphorus than the titanium oxide itself.

Increased in vitro $\mathrm{CaP}$-forming ability, as a consequence of biologically active D3 vitamin layer, could serve as a predictor of in vivo bioactivity of investigated surfaces.

The chemistry of Ti/oxide and Ti/oxide/D3 surfaces, before and after 1 month-immersion period, was examined by attenuated total reflection Fourier transform infrared spectroscopy (ATR-FTIR) and corresponding spectra are presented in Fig. (3). The spectra of as-prepared samples, recorded after the final step of modification (Section 2.1), are shown in Fig. (3a). In the Ti/oxide spectrum, a band at 351 $\mathrm{cm}^{-1}$ is related to the Ti-O stretching vibrations [31]. Upon the D3 layer formation on the Ti/oxide surface, a recorded response is more complex than a spectrum of the $\mathrm{Ti} /$ oxide sample. Bands characteristic for D3 vitamin can be observed in the spectra and are in accordance with literature data [19, 32]. The presence of a band located at $1643 \mathrm{~cm}^{-1}$ that is assigned to the $\mathrm{H}-\mathrm{C}=\mathrm{CH}$ stretching vibration confirms the formation of the D3 vitamin layer on the Ti/oxide surface. Furthermore, the Ti-O band at $351 \mathrm{~cm}^{-1}$ is also visible due to relatively low D3 layer thickness [19].

After 1 month-immersion in an artificial saliva solution, ATR-FTIR responses of both samples are different compared to responses of as-prepared samples, Fig. (3a, 3b). The assignation of bands was done according to published data $[25,26,29,33]$. Both samples show a broadband observed in the range from $3700-3000 \mathrm{~cm}^{-1}$ that corr sponds to adsorbed water molecule vibrations. A band auund $1639 \mathrm{~cm}^{-1}$ is also visible that can be assigned to water bending mode. In the case of the Ti/oxide/D3 sample, this band can be overlapped with band characteristic to $\mathrm{H}-\mathrm{C}=\mathrm{CH}$ stretching vibration of vitamin D3, Fig. (3a). The bands at $471\left(v_{2 b}\right), 480$ $\left(v_{2 \mathrm{a}}\right), 560\left(v_{4 \mathrm{c}}\right), 601\left(v_{4 \mathrm{a}}\right), 961\left(v_{1}\right), 1025\left(v_{3 \mathrm{c}}\right)$, and $1082 \mathrm{~cm}^{-1}$ $\left(v_{3 a}\right)$ correspond to $\mathrm{PO}_{4}^{3-}$ vibrations and bands at 1456 $\left(v_{4} / v_{3}\right), 1417\left(v_{3}\right)$ and $861 \mathrm{~cm}^{-1}\left(v_{3}\right)$ indicate the presence of carbonate ions, $\mathrm{CO}_{3}^{2-}$. A weak band at $1539 \mathrm{~cm}^{-1}$ is assigned to $\mathrm{n}(\mathrm{O}=\mathrm{C}-\mathrm{NH})[34]$ and originates from urea, a component of the artificial saliva in which samples were immersed.

Absorption bands and their locations in ATR-FTIR spectra point to the formation of $\mathrm{CaP}$ deposits on both samples, Ti/oxide and Ti/oxide/D3 during their 1 month-immersion in an artificial saliva solution which is in accordance with SEM and EDS results, Figs. (1, 2). The appearance of carbonate ions in the $\mathrm{CaP}$ structure is quite reasonable since atmospheric $\mathrm{CO}_{2}$ could diffuse into the artificial saliva solution during 1 month-immersion period. Additional confirmation of carbonate substitution in the $\mathrm{CaP}$ structure is the absence of a characteristic $\mathrm{OH}$ band at around $3570 \mathrm{~cm}^{-1}$ which can be an indication of non-well-crystallized CaP deposits [25, 29]. The carbonate content makes coatings more similar to the natural bone mineral composition [33]. It needs to be pointed out that band intensities of the Ti/oxide/D3 sample are higher compared to intensities of the Ti/oxide sample which indicates a higher $\mathrm{CaP}$ amount on the Ti/oxide/D3 surface and it is in accordance with SEM results.

Based on ATR-FTIR, SEM and EDS results, it could be concluded that the vitamin D3 layer had a strong influence on the spontaneous $\mathrm{CaP}$ formation, which means that the surfaces thus prepared exhibited improved bioactivity and osseointegration. In other words, implants whose surface has a greater affinity for spontaneous $\mathrm{CaP}$ formation, a material of composition resembling human bone, will osseointegrate faster with natural bone compared to implants without bioactive surface. These CaP deposits on the D3 vitamin-coated surfaces could act as possible graft materials for a new bone tissue formation.

\subsection{Wetting Properties of Ti Samples}

The wetting properties of Ti surfaces before and after the 1 -month immersion period in an artificial saliva solution were investigated by measuring a static contact angle $\theta$ and the results are provided in Table $\mathbf{1}$. Wetting properties differences were clearly observed between as-prepared Ti/oxide and Ti/oxide/D3 surfaces. The water contact angle value of 
a)

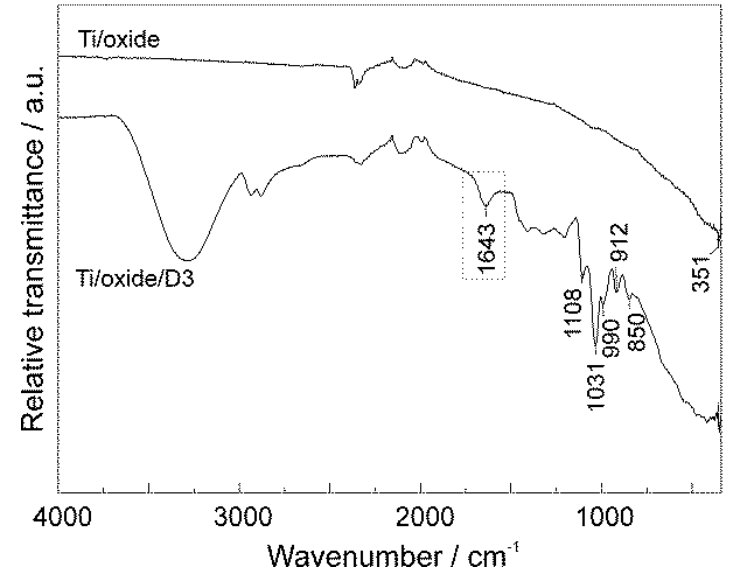

b)

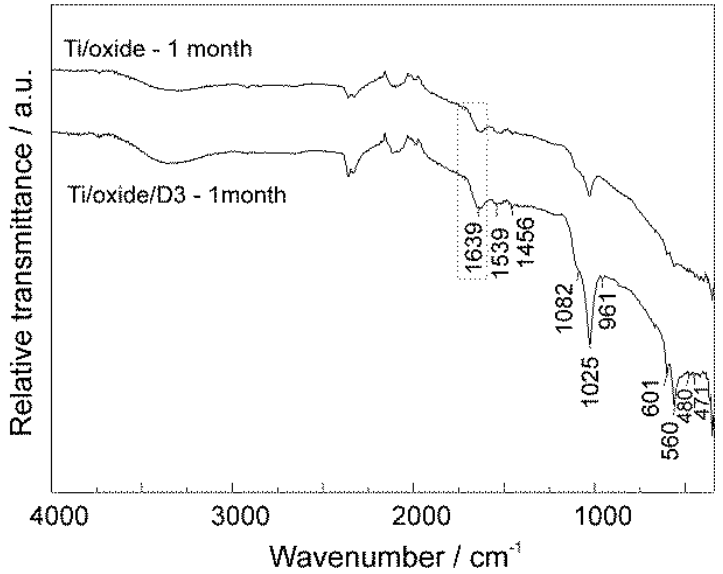

Fig. (3). ATR-FTIR spectra of (a) as-prepared Ti/oxide and Ti/oxide/D3 samples; and (b) after their 1 month-immersion period in the artificial saliva solution. (A higher resolution / colour version of this figure is available in the electronic copy of the article).

the Ti/oxide surface was significantly lower $\left(9.4^{\circ}\right)$ compared to the value measured on the Ti/oxide/D3 surface $\left(42.8^{\circ}\right)$ and pointed to a high hydrophilic character, i.e. an increased wettability of the Ti/oxide surface. Since the oxide film was anodically prepared in a phosphate buffer solution, hydroxyl groups $(-\mathrm{OH})$ present in the outer part of the oxide film, interacted with $\mathrm{H}_{2} \mathrm{O}$ drop. Upon a D3 vitamin modification of the Ti/oxide surface, a water contact angle value increased and pointed to a more hydrophobic nature of the surface. As confirmed by our previous DFT results [19], vitamin D3 molecules are bonded to the oxide surface via the Ti-O bond and methyl group $\left(-\mathrm{CH}_{3}\right)$ as the terminal functional group determines the coating's surface properties. The obtained results confirmed a successful vitamin D3 layer formation on the Ti/oxide surface.

After a 1-month immersion period, contact angle values of both samples were changed due to the precipitation of $\mathrm{CaP}$ deposits as was confirmed by SEM, EDS, and ATRFTIR results, Figs. (1c, d-3).

In the field of biomedical applications, solid surface properties and interfacial interactions are of special interest and are determined by the surface free energy. Thus, knowledge of surface free energy values can predict behavior of implant/bone and implant/surrounding body fluids interactions. Based on contact angle values, the total surface free energy, $\gamma_{\mathrm{s}}$ and its polar, $\gamma_{\mathrm{s}}^{p}$ and dispersive, $\gamma_{\mathrm{s}}^{d}$ components of Ti/oxide and Ti/oxide/D3 surfaces were calculated using the Wu's harmonic mean approach, which is an appropriate model for determining the surface free energy of nonpolar surfaces like organic liquids and solids [35]:

$\gamma_{\mathrm{lv}}(1+\cos \theta)=\frac{4 \gamma_{\mathrm{s}}^{\mathrm{d}} \gamma_{1}^{\mathrm{d}}}{\gamma_{\mathrm{s}}^{\mathrm{d}}+\gamma_{1}^{\mathrm{d}}}+\frac{4 \gamma_{\mathrm{s}}^{\mathrm{p}} \gamma_{1}^{\mathrm{p}}}{\gamma_{\mathrm{s}}^{\mathrm{p}}+\gamma_{1}^{\mathrm{p}}}$

where $\theta$ is the contact angle, $\gamma_{\mathrm{lv}}$ is the interfacial liquidvapor free energy, $\gamma_{1}^{d}, \gamma_{\mathrm{s}}^{d}$ are the dispersive components of the surface free energy of liquid and solid, respectively, and $\gamma_{1}^{p}, \gamma_{\mathrm{s}}^{p}$ are the polar components of the surface free energy of liquid and solid, respectively. The surface free energy components of solid $\left(\gamma_{\mathrm{s}}^{p}, \gamma_{\mathrm{s}}^{d}\right)$ for investigated samples were cal- culated using numerical values of experimentally determined contact angles and results are given in Table 1 .

ccording to the total surface free energy value and its components for the as-prepared Ti/oxide sample, the polar component of the surface free energy dominates over the dispersion component. A polar nature of the anodically formed oxide film is a consequence of $-\mathrm{OH}$ groups (present in the outer part of the oxide film) interactions with water molecules via $\mathrm{H}$-bonding. Upon a D3 vitamin modification of the oxide surface, the total surface free energy value decreased compared to the value measured on the Ti/oxide surface due to the presence of a non-polar low-energy component D3 layer, which contains hydrophobic $\left(-\mathrm{CH}_{2}\right.$ and $\left.\mathrm{CH}_{3}\right)$ groups. The dispersion component of the surface free energy prevails since surface interactions in the vitamin D3 layer are characterized by van der Waals interactions. It is important to point out that a polar component of the surface free energy is not negligible due to the existence of $\mathrm{C}-\mathrm{H} \cdots \mathrm{O}$ hydrogen bonds in the vitamin D3 layer as shown in our DFT study [19].

After 1 month-immersion of the Ti/oxide sample, a decrease of the total surface free energy was induced by a significant decrease of the polar component of the surface free energy (Table 1). Due to spontaneous deposition of the inorganic material, $\mathrm{CaP}$ on the oxide surface, $\mathrm{H}$-bonding between $-\mathrm{OH}$ groups and water drop were replaced by $\mathrm{CaP}$ water interactions.

The total surface free energy of the Ti/oxide/D3 sample remained nearly unaltered after a prolonged immersion in an artificial saliva solution. Almost equal changes in polar and dispersion component values of the surface free energy before and after spontaneous $\mathrm{CaP}$ deposition can be observed in Table 1. The polar component of the surface free energy increased after a 1-month immersion period due to dipoledipole (adsorbed water - water drop) and/or ion-dipole (phosphate group - water drop and trace elements - water drop) interactions. The presence of water molecules, as well as trace elements (ions like $\mathrm{Cl}^{-}$), was confirmed by ATRFTIR Fig. (3) and EDS Fig. (2b) results. Additionally, the dispersion component of the surface free energy was present, 
Table 1. Values of contact angles, total surface free energy $\left(\gamma_{s}\right)$ and its polar $\left(\gamma_{s}^{p}\right)$ and dispersive $\left(\gamma_{s}^{d}\right)$ components of the Ti samples.

\begin{tabular}{|c|c|c|c|c|c|c|}
\hline Samples & $q\left(\mathrm{CH}_{2} \mathrm{I}_{2}\right) /^{0}$ & $q\left(\mathrm{HCONH}_{2}\right) /^{0}$ & $q\left(\mathbf{H}_{2} \mathbf{O}\right) /^{o}$ & $\gamma_{\mathrm{s}}^{p} / \mathbf{m} \mathbf{J} \mathbf{m}^{-2}$ & $\gamma_{\mathrm{s}}^{d} / \mathbf{m} \mathbf{J ~ m}^{-2}$ & $\gamma_{\mathrm{s}} / \mathbf{m J ~ m}^{-2}$ \\
\hline Ti/oxide/D3 & $44.4 \pm 1.9$ & $41.7 \pm 1.3$ & $42.8 \pm 1.1$ & 23.9 & 30.3 & 54.2 \\
\hline \multicolumn{7}{|c|}{ After 1-month immersion in artificial saliva } \\
\hline Ti/oxide/D3 & $66.2 \pm 2.2$ & $54.2 \pm 2.2$ & $36.0 \pm 1.9$ & 34.7 & 22.4 & 57.1 \\
\hline
\end{tabular}

a)

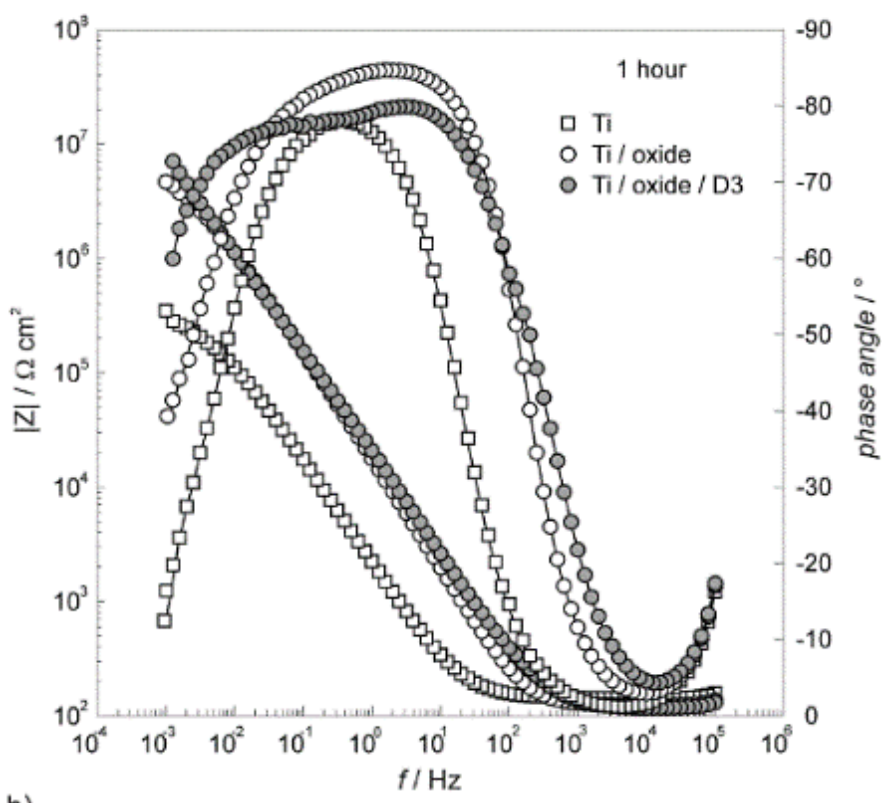

b)

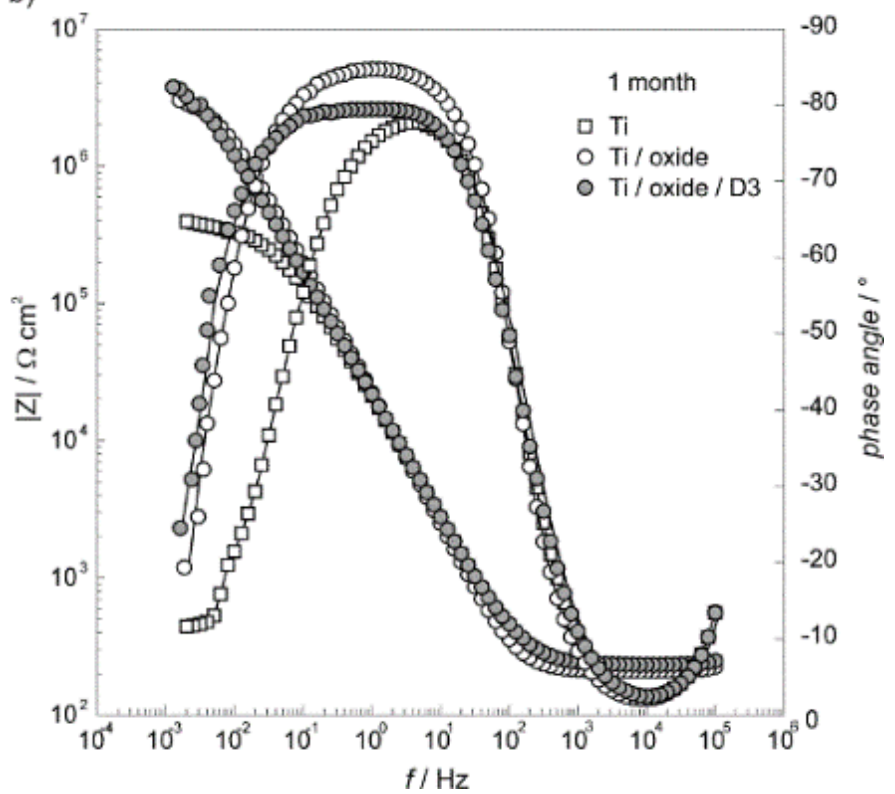

Fig. (4). The Bode plots of $\mathrm{Ti}$, Ti/oxide, and Ti/oxide/D3 samples recorded at $E_{\mathrm{OC}}$ in the artificial saliva solution, $\mathrm{pH} 6.8$ after immersion period of (a) 1 hour and (b) 1 month. Symbols: the experimental data; solid lines: the modeled data. (A higher resolution / colour version of this figure is available in the electronic copy of the article). 
since irregular $\mathrm{CaP}$ islands partially cover the surface and therefore, the water drop can simultaneously sense the D3 coating on the surface as well.

\subsection{Corrosion Properties of Ti Samples in Artificial Sali- va Solution}

The corrosion properties of titanium, Ti/oxide, and Ti/oxide/D3 samples were examined by electrochemical impedance spectroscopy (EIS), a reliable non-destructive technique for in situ examination of the corrosion behavior of (un)coated metallic materials. Investigations were performed in an artificial saliva solution electrolyte, $\mathrm{pH} 6.8$, at the open circuit potential, $E_{\mathrm{OC}}$ over the wide frequency range after an electrolyte-exposure period of 1 hour and 1 month and the results are presented in Fig. (4). For comparison to modified Ti samples, EIS results of the unmodified Ti sample (Ti) are also presented.

The EIS data obtained were modeled to the Electric Equivalent Gircuit (EEC) consisting of two-time constants in a parallel combination connected in series with ohmic (electrolyte) resistance, $R_{\mathrm{el}}-$ EEC was schematically given as $R_{\mathrm{el}}\left(\mathrm{CPE}_{1}\left(R_{1}\left(\mathrm{CPE}_{2} R_{2}\right)\right)\right)$. The Constant Phase Element (CPE) was utilized instead of a capacitor in order to take into account various system's non-homogeneous behavior occurrences (e.g., electrode surface heterogeneity, inhomogeneous current flow, capacitance dispersion) [36, 37]. The CPE is characterized by $\mathrm{CPE}$ frequency-independent constant, $Q$ and CPE power $n$ as impedance parameters correlated in empirical impedance function $Z_{\mathrm{CPE}}=\left[Q(\mathrm{j} \omega)^{\mathrm{n}}\right]^{-1}$ where $\omega$ is the angular frequency [36]. The ideal capacitor is described by $n=1$, whilst upon surface heterogeneity, the existence of surface films or continuously distributed time constants for charge-transfer reactions $n \neq 1$ [36]. For $\mathrm{n}$ values higher than 0.8 , the interface capacitance values were assessed employing Brug's equation [37]:

$C=Q^{1 / \mathrm{n}}\left[R_{\mathrm{el}}^{-1}+R^{-1}\right]^{(\mathrm{n}-1) / \mathrm{n}}$

The impedance parameter values obtained by described EEC model utilization are given in Table $\mathbf{2}$.

For the Ti sample (Ti) and $\mathrm{Ti}$ sample coated by potentiostatically formed oxide film (Ti/oxide) provided impedance parameters can be correlated to the bi-layered oxide film structure formed on the titanium as a typical model for surface oxide films formed on valve metals including titanium $[19,38-40]$. It is known that the titanium surface is always covered by a very thin, spontaneously formed protective passive film. Therefore, the first time constant $\left(\mathrm{CPE}_{1}-R_{1}\right)$, $\mathrm{high} /$ middle frequency region, is attributed to the outer part of the oxide layer spontaneously or potentiostatically formed on the Ti surface with $R_{1}$ as the resistance and $Q_{1}$ as the interfacial capacitance of the oxide outer part. The second time constant $\left(\mathrm{CPE}_{2}-R_{2}\right)$, low-frequency region, is ascribed to the inner part of the oxide layer mostly composed of titanium (IV) oxide $[12,41]$ with $\mathrm{CPE}_{2}$ and $R_{2}$ corresponding to the capacitance and the resistance of the oxide inner layer. As can be seen from Table 2, structural sensitive parameter, CPE power $n$ indicates a porous nature of the outer part $\left(n_{1}\right)$ and a more compact inner part $\left(\mathrm{n}_{2}\right)$ of both samples. However, the potentiostatically formed oxide film exhibits higher $R_{2}$ value attributed to the formation of more compact and corrosion-resistant oxide film.
On the other hand, for the (Ti/oxide/D3) sample, the twotime constants are related to the outer and inner part of the surface coating - vitamin D3 layer over the oxide layer formed. The phase angle as structural sensitive value reflects changes inside the interfacial layer upon (Ti/oxide) surface functionalization by the vitamin D3 layer, Fig. (4a). Induced changes are also reflected in CPE power $n_{1}$ value that significantly increased compared to $n_{1}$ values of $\mathrm{Ti}$ and Ti/oxide samples (Table 2). The result indicates that vitamin D3 molecules covered / filled in imperfections of the oxide film and the resulting coating (oxide + D3 layer) acted as an effective barrier between the electrolyte and the underlying titanium as can be noticed from significantly increased $R_{2}$ values (in order of $10^{7} \Omega \mathrm{cm}^{2}$ ). Since overall corrosion resistance of investigated samples in an artificial saliva solution is defined by the sum of both $R_{1}$ and $R_{2}$ resistance values equal to the corrosion (polarization) resistance, $R_{\mathrm{p}}$ [42], the subsequent formation of vitamin D3 layer over the oxide layer significantly improved overall corrosion resistance of the underlying Ti sample.

In order to predict a long-term electrochemical/chemical stability of dental implant materials in an aggressive medium such as oral cavity fluids, corrosion behavior of investigated samples in an artificial saliva solution after 1-month immersion period was examined by EIS and results are presented in Fig. (4b) and Table 2. As can be seen from Table 2, the prolonged immersion period affected the outer part of the surface films what is reflected in the $R_{1}$ values. In more detail, the Ti sample, covered by the spontaneously formed oxide film, exhibited alike impedance parameters during 1 month immersion period, whilst Ti/oxide and Ti/oxide/D3 samples exhibited higher $R_{1}$ values related to the spontaneous formation of calcium phosphate $(\mathrm{CaP})$ agglomerates on the modified Ti surfaces compared to the Ti sample. The spontaneous $\mathrm{CaP}$ formation is corroborated by SEM/EDS, ATRFTIR, and contact angle measurement results, Figs. (1-3).

The overall corrosion resistance of the Ti/oxide and Ti/oxide/D3 samples, determined by both resistance contributions, decreased during exposure to an artificial saliva solution, which is particularly reflected in $R_{2}$ values. As it is evident from Figs. $\left(\mathbf{4 a}, \mathbf{4 b}\right.$ ) (phase angle $>-90^{\circ}$ ) and CPE power $\mathrm{n}$ values, $\mathrm{n}<1$, all investigated samples do not behave as ionic insulators due to microstructural imperfections in the coatings' structure, which most likely originate from coating formation procedure. These imperfections allowed ion/water penetration through the coating to the underlying titanium. Since the artificial saliva solution represents an aggressive medium, a high amount of chloride ions affects the surface film properties and accelerates the titanium corrosion process during a prolonged immersion period $[19,40]$. The spontaneously formed fluffy $3 \mathrm{D} \mathrm{CaP}$ clusters, which partially cover Ti/oxide and Ti/oxide/D3 surfaces, do not provide additional corrosion protection to the titanium, but make its surface osseoinductive which is of great importance in dental implantology application.

The corrosion protection effectiveness, $\eta$, of the coated Ti surface can be calculated using the relation: $\eta=\left(R_{\mathrm{p}(\text { modified })}\right.$ $\left.R_{\mathrm{p}(\text { unmodified) })}\right) / R_{\mathrm{p} \text { (modified) })}$ where $R_{\mathrm{p} \text { (unmodified) }}$ and $R_{\mathrm{p} \text { (modified) }}$ are the polarization resistances of unmodified (Ti) and modified Ti (Ti/oxide and Ti/oxide/D3) samples. Despite the de- 
Table 2. Impedance parameters calculated for EIS data of Ti samples recorded at $E_{\mathrm{OC}}$ in the artificial saliva solution, pH 6.8 after different immersion periods denoted.

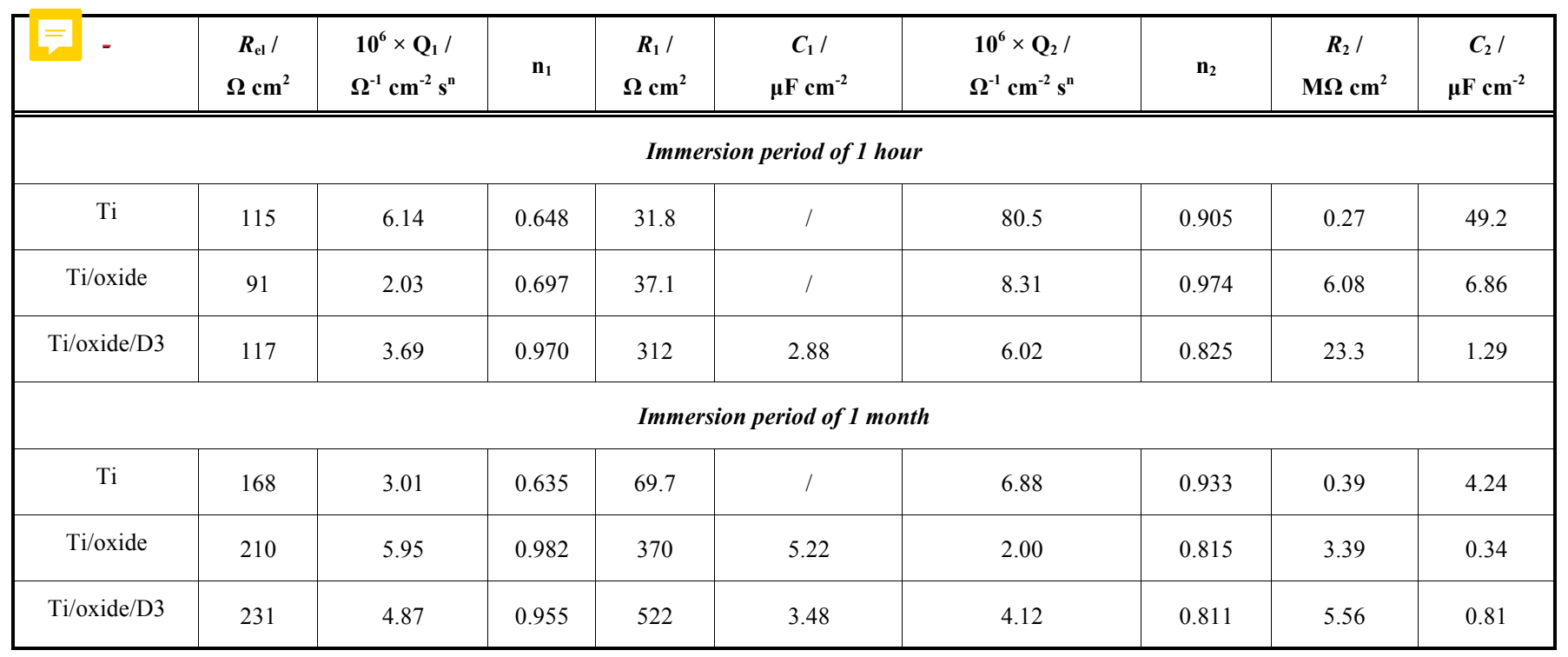

creased resistance values, the overall corrosion resistance (protection effectiveness) after 1-month immersion is $92.0 \%$ and $95.1 \%$ for Ti/oxide and Ti/oxide/D3 interfaces, respectively. Thus, surface films formed impart good corrosion protection level to the underlying Ti material.

In conclusion, titanium material's surface functionalization by vitamin D3 coating resulted in improved corrosion resistance in aggressive cavity fluids (artificial saliva solution), under real dental implant application conditions. At the same time, the spontaneously induced formation of bone-like calcium phosphates on the D3 vitamin modified Ti surface during prolonged exposure to artificial saliva solution confirmed enhanced titanium's bioactivity level.

\section{CONCLUSION}

The titanium surface was modified by the potentiostatically formed oxide and the vitamin D3 coating over the oxide. The influence of prepared coatings on titanium surface characteristics was examined by SEM/EDS, ATR-FTIR, contact angle, and EIS measurements. Results of all techniques confirmed a successful formation of both coatings on the titanium surface.

The long-term electrochemical/chemical stability of coated titanium samples during exposure to the artificial saliva solution was investigated in situ by using EIS and results were modeled employing an electrical equivalent circuit. Results point to decreased overall corrosion resistivity of the Ti/oxide/D3 as well as Ti/oxide samples after a 1-month immersion period compared to values measured after a 1hour immersion period. Ion/water penetration into coatings' structure to the underlying titanium was enabled through structural imperfections which caused the titanium corrosion process. However, surface coatings imparted good corrosion protection level to the titanium, since overall protection effectiveness, after 1-month immersion, amounts $95.1 \%$ and $92.0 \%$ for $\mathrm{Ti} /$ oxide/D3 and $\mathrm{Ti} /$ oxide, respectively.
The spontaneous formation of biocompatible bone-like calcium phosphates $(\mathrm{CaP})$ during prolonged immersion in the artificial saliva solution was observed on Ti/oxide/D3 and Ti/oxide surfaces by SEM/EDS, ATR-FTIR, and contact angle measurements. ATR-FTIR and SEM results point out a higher $\mathrm{CaP}$ amount on the Ti/oxide/D3 surface compared to the amount on the Ti/oxide surface.

The results presented could be useful for designing dental implant surfaces of good anti-corrosion properties and at the same time of improved bioactivity. Formed CaP layer can impact interplay of osseointegration and bone growth and in turn result in successful implantation and longer life-time of implants.

\section{CONSENT FOR PUBLICATION}

Not applicable.

\section{AVAILABILITY OF DATA AND MATERIALS}

Not applicable.

\section{FUNDING}

This research received no external funding.

\section{CONFLICT OF INTEREST}

The authors declare no conflict of interest.

\section{ACKNOWLEDGEMENTS}

This work has been partially supported by SAFU, project KK.01.1.1.01.0001.

\section{REFERENCES}

[1] P.I. Brånemark, R. Adell, U. Breine, B.O. Hansson, J. Lindström, and A. Ohlsson, "Intra-osseous anchorage of dental prostheses. I. Experimental studies", Scand. J. Plast. Reconstr. Surg., vol. 3, no. 2, pp. 81-100, 1969. 
http://dx.doi.org/10.3109/02844316909036699 PMID: 4924041

[2] P.I. Brånemark, R. Adell, T. Albrektsson, U. Lekholm, S. Lundkvist, and B. Rockler, "Osseointegrated titanium fixtures in the treatment of edentulousness", Biomaterials, vol. 4, no. 1, pp. 25-28, 1983.

http://dx.doi.org/10.1016/0142-9612(83)90065-0 PMID: 6838955

[3] L. Gaviria, J.P. Salcido, T. Guda, and J.L. Ong, "Current trends in dental implants", J. Korean Assoc. Oral Maxillofac. Surg., vol. 40, no. 2 , pp. $50-60,2014$

http://dx.doi.org/10.5125/jkaoms.2014.40.2.50 PMID: 24868501

[4] R. Smeets, B. Stadlinger, F. Schwarz, B. Beck-Broichsitter, O. Jung, C. Precht, F. Kloss, A. Gröbe, M. Heiland, and T. Ebker, "Impact of Dental Implant Surface Modifications on Osseointegration", BioMed Res. Int., vol. 2016, 2016.6285620

http://dx.doi.org/10.1155/2016/6285620 PMID: 27478833

[5] O.M. Al Mugeiren, and M.A. Baseer, "Dental Implant Bioactive Surface Modifiers: An Update", J. Int. Soc. Prev. Community Dent., vol. 9, no. 1, pp. 1-4, 2019.

http://dx.doi.org/10.4103/jispcd.JISPCD_303_18 PMID: 30923686

[6] A.H. Choi, B. Ben-Nissan, J.P. Matinlinna, and R.C. Conway, "Current perspectives: calcium phosphate nanocoatings and nanocomposite coatings in dentistry", J. Dent. Res., vol. 92, no. 10, pp. 853-859, 2013.

http://dx.doi.org/10.1177/0022034513497754 PMID: 23857642

[7] T.T. Hägi, L. Enggist, D. Michel, S.J. Ferguson, Y. Liu, and E.B. Hunziker, "Mechanical insertion properties of calcium-phosphate implant coatings", Clin. Oral Implants Res., vol. 21, no. 11, pp. 1214-1222, 2010.

http://dx.doi.org/10.1111/j.1600-0501.2010.01916.x PMID: 20546252

[8] C. von Wilmowsky, T. Moest, E. Nkenke, F. Stelzle, and K.A. Schlegel, "Implants in bone: part I. A current overview about tissue response, surface modifications and future perspectives", Oral Maxillofac. Surg., vol. 18, no. 3, pp. 243-257, 2014.

http://dx.doi.org/10.1007/s10006-013-0398-1 PMID: 23435578

[9] B. Peter, D.P. Pioletti, S. Laïb, B. Bujoli, P. Pilet, P. Janvier, J. Guicheux, P.Y. Zambelli, J.M. Bouler, and O. Gauthier, "Calcium phosphate drug delivery system: influence of local zoledronate release on bone implant osteointegration", Bone, vol. 36, no. 1, pp. 52-60, 2005.

http://dx.doi.org/10.1016/j.bone.2004.10.004 PMID: 15664002

[10] J. Abtahi, P. Tengvall, and P. Aspenberg, "A bisphosphonatecoating improves the fixation of metal implants in human bone. A randomized trial of dental implants", Bone, vol. 50, no. 5, pp. 1148$1151,2012$.

http://dx.doi.org/10.1016/j.bone.2012.02.001 PMID: 22348981

[11] L. Rojo, B. Gharibi, R. McLister, B.J. Meenan, and S. Deb, "Selfassembled monolayers of alendronate on Ti6Al4V alloy surfaces enhance osteogenesis in mesenchymal stem cells", Sci. Rep., vol. 6, p. $30548,2016$.

http://dx.doi.org/10.1038/srep30548 PMID: 27468811

[12] D.C. Hansen, "Metal Corrosion in the Human Body: The Ultimate Bio-Corrosion Scenario", Electrochem. Soc. Interface, vol. ‥, p. 4, 2008.

[13] N. Eliaz, "Corrosion of Metallic Biomaterials: A Review", Materials (Basel), vol. 12, no. 3, pp. 407-498, 2019. http://dx.doi.org/10.3390/ma12030407 PMID: 30696087

[14] A. Sicilia, S. Cuesta, G. Coma, I. Arregui, C. Guisasola, E. Ruiz, and A. Maestro, "Titanium allergy in dental implant patients: a clinical study on 1500 consecutive patients", Clin. Oral Implants Res., vol. 19, no. 8, pp. 823-835, 2008.

http://dx.doi.org/10.1111/j.1600-0501.2008.01544.x PMID: 18705814

[15] M. Syed, R. Chopra, and V. Sachdev, "Allergic Reactions to Dental Materials-A Systematic Review", J. Clin. Diagn. Res., vol. 9, no. 10, pp. ZE04-ZE09, 2015.

http://dx.doi.org/10.7860/JCDR/2015/15640.6589 PMID: 26557634

[16] H. Yan, S. Afroz, J. Dalanon, N. Goto, M. Hosoki, and Y. Matsuka, "Metal allergy patient treated by titanium implant denture: A case report with at least 4-year follow-up", Clin. Case Rep., vol. 6, no. 10, pp. 1972-1977, 2018.

http://dx.doi.org/10.1002/ccr3.1753 PMID: 30349710

[17] G. Trybek, M. Aniko-Włodarczyk, and J. Kwiatek, "The effect of vitamin D3 on the osteointegration of dental implants article details", Balt J Health Phys Act, vol. 10, pp. 25-33, 2018.
http://dx.doi.org/10.29359/BJHPA.10.4.02

[18] G.J. Atkins, P.H. Anderson, D.M. Findlay, K.J. Welldon, C. Vincent, A.C. Zannettino, P.D. O'Loughlin, and H.A. Morris, "Metabolism of vitamin D3 in human osteoblasts: evidence for autocrine and paracrine activities of $1 \alpha, 25$-dihydroxyvitamin D3", Bone, vol. 40, no. 6, pp. 1517-1528, 2007. http://dx.doi.org/10.1016/j.bone.2007.02.024 PMID: 17395559

[19] J. Katić, A. Šarić, I. Despotović, N. Matijaković, M. Petković, and Ž. Petrović, "Bioactive Coating on Titanium Dental Implants for Improved Anticorrosion Protection: A Combined Experimental and Theoretical Study", Coatings, vol. 9, p. 612, 2019.

http://dx.doi.org/10.3390/coatings9100612

[20] R. Quiñones, and E.S. Gawalt, "Study of the formation of selfassembled monolayers on nitinol", Langmuir, vol. 23, no. 20, pp. 10123-10130, 2007.

http://dx.doi.org/10.1021/la701110p PMID: 17725369

[21] A. Boukamp, "A Nonlinear Least Squares Fit procedure for analysis of immittance data of electrochemical systems", Solid State Ion., vol. 20, pp. 31-44, 1986.

http://dx.doi.org/10.1016/0167-2738(86)90031-7

[22] A. Mellado-Valero, A.I. Muñoz, V.G. Pina, and M.F. Sola-Ruiz, "Electrochemical Behaviour and Galvanic Effects of Titanium Implants Coupled to Metallic Suprastructures in Artificial Saliva", Materials (Basel), vol. 11, no. 1, pp. 171-190, 2018. http://dx.doi.org/10.3390/ma11010171 PMID: 29361767

[23] F.P. Zamborini, and R.M. Crooks, "Corrosion Passivation of Gold by n-Alkanethiol Self-Assembled Monolayers: Effect of Chain Length and End Group", Langmuir, vol. 14, pp. 3279-3286, 1998. http://dx.doi.org/10.1021/la971121o

[24] R.B. Heimann, and H.D. Lehmann, Bioceramics Coatings for Medical Implants: Trends and Techniques., 1st ed Wiley-VCH, 2015. http://dx.doi.org/10.1002/9783527682294

[25] K. Lin, Y. Zhou, and Y. Zhou, "Biomimetic hydroxyapatite porous microspheres with co-substituted essential trace elements: Surfactant-free hydrothermal synthesis, enhanced degradation and drug release", J. Mater. Chem., vol. 21, pp. 16558-16565, 2011.

http://dx.doi.org/10.1039/c1jm12514a

[26] L. Berzina-Cimdina, and N. Borodajenko, Research of Calcium Phosphates Using Fourier Transform Infrared Spectroscopy.Infrared Spectroscopy - Materials Science, Engineering and Technology [Internet]., vol. Chapter 6. IntechOpen: Rijeka, 2012. http://dx.doi.org/10.5772/36942

[27] I. Buljan Meić, J. Kontrec, and D. Domazet Jurašin, "Comparative Study of Calcium Carbonates and Calcium Phosphates Precipitation in Model Systems Mimicking the Inorganic Environment for Biomineralization", Cryst. Growth Des., vol. 17, pp. 1103-1117, 2017.

http://dx.doi.org/10.1021/acs.cgd.6b01501

[28] K. Lin, C. Wu, and J. Chang, "Advances in synthesis of calcium phosphate crystals with controlled size and shape", Acta Biomater., vol. 10, no. 10, pp. 4071-4102, 2014.

http://dx.doi.org/10.1016/j.actbio.2014.06.017 PMID: 24954909

[29] V. Zalite, and J. Locs, "Characterization of Different Hydroxyapatite Particles for Tooth Enamel Remineralization", Key Eng. Mater., vol. 674, pp. 139-144, 2016.

http://dx.doi.org/10.4028/www.scientific.net/KEM.674.139

[30] V. Veldurthy, R. Wei, L. Oz, P. Dhawan, Y.H. Jeon, and S. Christakos, "Vitamin D, calcium homeostasis and aging", Bone Res., vol. 4, p. 16041, 2016.

http://dx.doi.org/10.1038/boneres.2016.41 PMID: 27790378

[31] C.C. Ferreira, V.P. Ricci, L.L. de Sousa, N.A. Mariano, and M.G.N. Campos, "Improvement of Titanium Corrosion Resistance by Coating with Poly-Caprolactone and PolyCaprolactone/Titanium Dioxide: Potential Application in Heart Valves", Mater. Res., vol. 20, pp. 126-133, 2017. http://dx.doi.org/10.1590/1980-5373-mr-2017-0425

[32] R. Othayoth, P. Mathi, K. Bheemanapally, L. Kakarla, and M. Botlagunta, "Characterization of vitamin-cisplatin-loaded chitosan nano-particles for chemoprevention and cancer fatigue", J. Microencapsul., vol. 32, no. 6, pp. 578-588, 2015.

http://dx.doi.org/10.3109/02652048.2015.1065921

PMID: 26218628

[33] S.V. Dorozhkin, "Amorphous calcium (ortho)phosphates", Acta Biomater., vol. 6, no. 12, pp. 4457-4475, 2010. http://dx.doi.org/10.1016/j.actbio.2010.06.031 PMID: 20609395 
[34] P.H.H. Fischer, and C.A. Mcdowell, "The Infrared Absorption Spectra Of Urea-Hydrocarbon Adducts", Can. J. Chem., vol. 38, pp. 187-193, 1960.

http://dx.doi.org/10.1139/v60-025

[35] S. Wu, "Polar and Nonpolar Interactions in Adhesion", J. Adhes., vol. 5 , pp. 39-55, 1973.

http://dx.doi.org/10.1080/00218467308078437

[36] M.E. Orazem, and B. Tribollet, Electrochemical Impedance Spectroscopy., 2nd ed John Wiley \& Sons: New York, 2008. http://dx.doi.org/10.1002/9780470381588

[37] G.J. Brug, A.L.G. van den Eeden, M. Sluyters-Rehbach, and J.H. Sluyters, "The analysis of electrode impedances complicated by the presence of a constant phase element", J. Electroanal. Chem., vol. 176, pp. 275-295, 1984. http://dx.doi.org/10.1016/S0022-0728(84)80324-1

[38] J. Pan, D. Thierry, and C. Leygraf, "Electrochemical impedance spectroscopy study of the passive oxide film on titanium for implant application", Electrochim. Acta, vol. 41, pp. 1143-1153, 1996. http://dx.doi.org/10.1016/0013-4686(95)00465-3
[39] M. Aziz-Kerrzo, K.G. Conroy, A.M. Fenelon, S.T. Farrell, and C.B. Breslin, "Electrochemical studies on the stability and corrosion resistance of titanium-based implant materials", Biomaterials, vol. 22, no. 12, pp. 1531-1539, 2001.

http://dx.doi.org/10.1016/S0142-9612(00)00309-4 PMID: 11374452

[40] S. Tamilselvi, R. Murugaraj, and N. Rajendran, "Electrochemical impedance spectroscopic studies of titanium and its alloys in saline medium", Mater Corros, vol. 58, pp. 113-120, 2007.

http://dx.doi.org/10.1002/maco.200603979

[41] T. Kosec, A. Legat, J. Kovač, and D. Klobčar, "Influence of Laser Colour Marking on the Corrosion Properties of Low Alloyed Ti", Coatings, vol. 9, p. 375, 2019.

http://dx.doi.org/10.3390/coatings9060375

[42] J.R. Scully, "Polarization Resistance Method for Determination of Instantaneous Corrosion Rates", Corrosion, vol. 56, pp. 199-218, 2000.

http://dx.doi.org/10.5006/1.3280536 